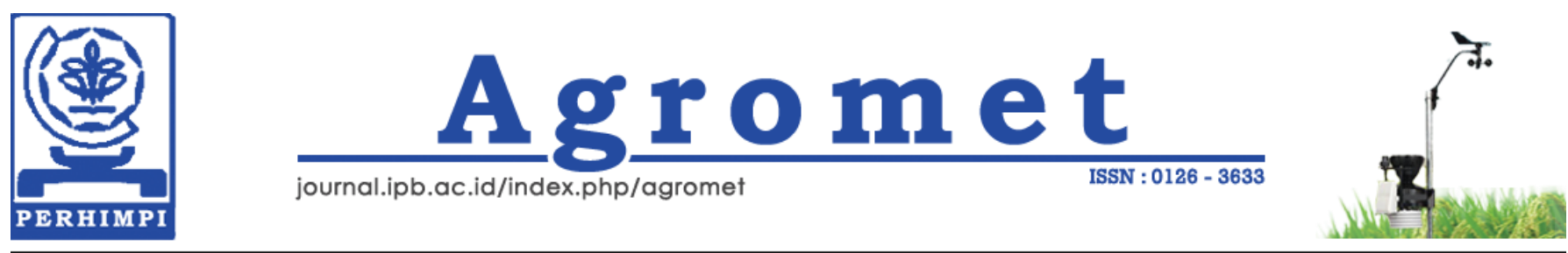

\title{
Evaluation of Different Runoff Curve Number (CN) Approaches on Water Regulation Services Assessment in Intermittent Micro Catchment Dominated by Oil Palm Plantation
}

\author{
Yudha Kristanto', Suria Darma Tarigan'2, Tania June ${ }^{3}$, Enni Dwi Wahjunie ${ }^{2}$ \\ ${ }^{1}$ Watershed Management Science, Department of Soil Science and Land Resources, Faculty of Agriculture, IPB University , \\ Dramaga Campus, Bogor, Indonesia 16680 \\ ${ }^{2}$ Department of Soil Science and Land Resources, Faculty of Agriculture, IPB University, Dramaga Campus, \\ Bogor, Indonesia 16680 \\ ${ }^{3}$ Department of Geophysics and Meteorology, Faculty of Mathematics and Natural Sciences, IPB University, Dramaga Campus, \\ Bogor, Indonesia 16680
}

\section{ARTICLE INFO}

\section{Received}

19 April 2021

\section{Revised}

23 June 2021

\section{Accepted for Publication}

19 July 2021

\section{Published}

31 August 2021

doi: 10.29244/j.agromet.35.2.73-88

\section{Correspondence:}

Yudha Kristanto

Watershed Management Science,

Department of Soil Science and Land Resources, Faculty of Agriculture, IPB University, Dramaga Campus, Bogor, Indonesia 16680

Email:

yudha_kristanto@apps.ipb.ac.id

This is an open-access article distributed under the CC BY License. (C) 2021 The Authors. Agromet.

\section{A B S T R A C T}

Surface runoff is a primary driving factor for water regulation services on oil palm plantations as it determines the hydrological components and other biogeochemical process. Therefore, understanding on their interaction and contribution within the watershed system is important to support decisionmaking system. Here, we applied Soil and Water Assessment Tools (SWAT) model to simulate water regulation services for an intermittent microcatchment dominated by oil palm plantation in Harapan Landscapes, Batanghari Regency, Jambi Province. In this study, we used two different runoff curve number $(\mathrm{CN})$ approaches in the SWAT model, namely the soil moisture curve number (CN-SM) and the plant evaporation curve number (CN-ET), to evaluate their applicability and uncertainty for assessing water regulation services. SWAT was automatically calibrated and validated against daily observed streamflow data. The results showed that the model performed well as indicated by hydrograph visual interpretation and statistical indicators. The performance was good for calibration and validation for both approaches with high R2 and Nash-Sutcliffe Efficiency (NSE). Also, the uncertainty was acceptable with P-factor $>70 \%$ and R-factor $<1$. Differences in CN-SM and CNET's conceptual structure have caused variations in the calibrated parameters' best-fit value and their sensitivity to streamflow simulations, which implicated for other components' output water regulation services. However, CN-ET approach was less responsive to area's biophysical conditions for runoff generation than CN-SM one. This implicated that CN-ET generated low soil water storage and an overestimated actual evapotranspiration. This modeling exercise showed selection of a runoff $\mathrm{CN}$ approach by considering biophysical characteristics is important for calculating and simulating water balance component in such watershed. The accuracy of the simulation will significantly influence watershed management recommendations to improve water regulation's sustainability.

KEYWORDS

plant evapotranspiration, soil moisture, streamflow, surface runoff, SWAT 


\section{INTRODUCTION}

Harapan Landscape, Batanghari Regency, Jambi Province, is one of the lowland landscapes in Sumatra island dominated by monoculture plantations of oil palm (Elaeis guineensis Jacq.) (Kii et al., 2020). Located in humid tropical region with intensive rainfall, high runoff associated with oil palm expansion is obvious due to a low infiltration rainwater (Hazrina and Risdiyanto, 2018; Merten et al., 2016; Tarigan et al., 2020). Surface runoff is a primary driving factor for water regulation services assessments on oil palm plantations because it greatly determines the amount of rainfall fill aquifers (Baiamonte, 2019; Verma et al., 2017; Widodo and Dasanto, 2010; Zhang et al., 2019). Also, surface runoff process in oil palm plantations, even for agricultural land in general, does not only determine the amount of streamflow (Chen et al., 2020), soil moisture (Liu et al., 2019), and evapotranspiration (Tarigan et al., 2020), but also has implications for the biogeochemical cycle and nutrient retention (Brito et al., 2019), water quality (Ba et al., 2020), erosion and sediment transport, and crop production (Sun et al., 2017).

Before the complex hydrological model was developed, according to Li et al., (2018) and Dash et al., (2020), previous researches observed the surface runoff and the hydrological process independently through field measurements. It is also modeled through a numerical equation for a single storage layer, such as Horton overland flow, Philips's infiltration, etc. However, that model cannot explain the complex spatial and temporal interaction between surface runoff and the other hydrological process inside the watershed system to support decision-making (Dash et al., 2020; June et al., 2018). Researchers then developed various hydrological models that can visualize the dynamic behavior of the hydrological system with simple equations to ease computation without reducing its physical aspects (Anees et al., 2016), such as Soil and Water Assessment Tool (SWAT) model (Arnold et al., 1998). The hydrological model focuses on simplicity and usability, where the causal relationship between hydrological input and output in a complex watershed system is emphasized to support integrated watershed management ( $\mathrm{Li}$ et al., 2018; Widyastuti and Taufik, 2019). Hydrological models are increasingly being developed and refined as a tool to manage land and water resources more effectively. However, because different models will replicate the hydrological process differently, the selected model must answer the research problems effectively and efficiently.

SWAT model is a physical-based hydrological model that is semi-spatially distributed and temporally continuous (Arnold et al., 1998). In addition to simulating the hydrological process, SWAT model has ability to simulate various main processes in the watershed ecosystem in the long-term period (Wei et al., 2018), such as nutrient cycle, plant growth, and sediment transport under land use and climate changes. This ability has made SWAT model is widely used as a watershed ecosystem management tool (Wang et al., 2019). The original SWAT model provides two userselectable surface runoff generation methods: The Green-Ampt infiltration method for sub-daily routing and the runoff Curve Number (CN) method for daily routing (Neitsch et al., 2015). Runoff CN method was developed by USDA Natural Resources Conservation Services, previously Soil Conservation Services (SCS), and still popularly known as the SCS-CN method (Baiamonte, 2019). Runoff $\mathrm{CN}$ has become the most preferred and widely applied in the most hydrologic simulation model because of its simplicity, less parameters, stable, and predictable (Kannan et al., 2008; Verma et al., 2017; Zhang et al., 2019).

The runoff $\mathrm{CN}$ method is an empirical method based on a simple conceptual relationship between surface runoff, daily rainfall, land use and management, and soil type without weakening the physical processes between these factors (Hawkins et al., 2019; Karlberg and Dile, 2016). This model was developed to provide consistent standards for estimating surface runoff over a wide range of land uses, land management, and soil characteristics. Slope adjustments can also be selected to see variations in the curve numbers due to variation in slope classes, especially in a steep-slope watershed (Ajmal et al., 2020). Since development of SWAT version 2005 (Neitsch et al., 2015), SWAT provides two approaches for calculating the daily $\mathrm{CN}$, soil moisture curve number (CN-SM) as an original approach and plant evaporation curve number (CN-ET) as a modified approach. CN-SM is the most common approach besides CN-ET, and several studies prefer to use the $\mathrm{CN}-\mathrm{SM}$ in hydrological modeling compared to the $\mathrm{CN}$ $\mathrm{ET}$. According to the original $\mathrm{CN}$ procedure, the $\mathrm{CN}-\mathrm{SM}$ allows the daily retention parameter $(\mathrm{S})$ to vary with the antecedent soil moisture condition (Neitsch et al., 2015). On the other hand, (CN-ET) allows the daily retention parameter to vary with the accumulated plant evapotranspiration in previous days. If the CN-ET is used in the simulation, the daily $\mathrm{CN}$ value does not depend on soil moisture but rather on antecedent climatic conditions.

Tarigan et al., (2020; 2018) have simulated water regulation services in tropical lowland areas of Jambi Provinces based on SWAT CN-SM. Hardly any research have been performed, which used SWAT CN-ET as a comparative method in that area. The default $\mathrm{CN}$ 
method in the SWAT model, $\mathrm{CN}-\mathrm{SM}$, may give precise outputs for some land biophysical characteristics but it may still generate exaggerated or underestimated outputs in some extents. The presence of two runoff $\mathrm{CN}$ on SWAT models also led to the emergence of structural uncertainty in the simulation, which was later implicated in the model output differences so that it requires a thorough consideration of the researcher. Therefore, this study seeks to evaluate CN-ET and CNSM's application in assessing water regulation services in tropical lowland areas dominated by oil palm plantations, with a case study of a micro catchment in the Harapan Landscape, Batanghari Regency, Jambi Province. Daily streamflow results from both approaches are calibrated and validated using daily streamflow observation data to test CN-ET and CN-SM applicability and uncertainty in hydrological simulation in the study area. The parameter calibration is carried out automatically with the SWAT-CUP (Soil and Water Assessment Tools-Calibration Uncertainty Program) because apart from performing parameter optimization and sensitivity analysis, SWAT-CUP also analyzes the level of uncertainty in applying the two methods in the study area (Abbaspour, 2015). Thus, the objectives of the research are:
(1) to analyze the sensitivity of CN-ET and CN-SM parameters to streamflow output,

(2) to calibrate, validate, and evaluate the structural uncertainty of the $\mathrm{CN}-\mathrm{SM}$ and $\mathrm{CN}-\mathrm{ET}$ approaches, and

(3) to evaluate the differences between CN-SM and $\mathrm{CN}-\mathrm{ET}$ in other water regulation services assessment than river discharge.

\section{RESEARCH METHODS}

\section{Study Site}

The study area on this research was a micro catchment where the entire area is a mature oil palm plantation planted in 2002 with a current plant height of approximately 14 meters. The area is 114.4 hectares, geographically located at $1^{\circ} 41^{\prime} 11.238^{\prime \prime}-1^{\circ} 42^{\prime} 14.137^{\prime \prime}$ $S$ and longitude $103^{\circ} 23^{\prime} 18.420^{\prime \prime}-103^{\circ} 23^{\prime} 50.208^{\prime \prime} E_{\text {, }}$ and has an elevation range of 24-81 meters. The micro catchment is part of the Batanghari watershed, which is administratively located in Bajubang District, Batanghari Regency, Jambi Province. River networks are categorized as intermittent rivers, where the streamflow only occurs at certain times after rains, and the stream-

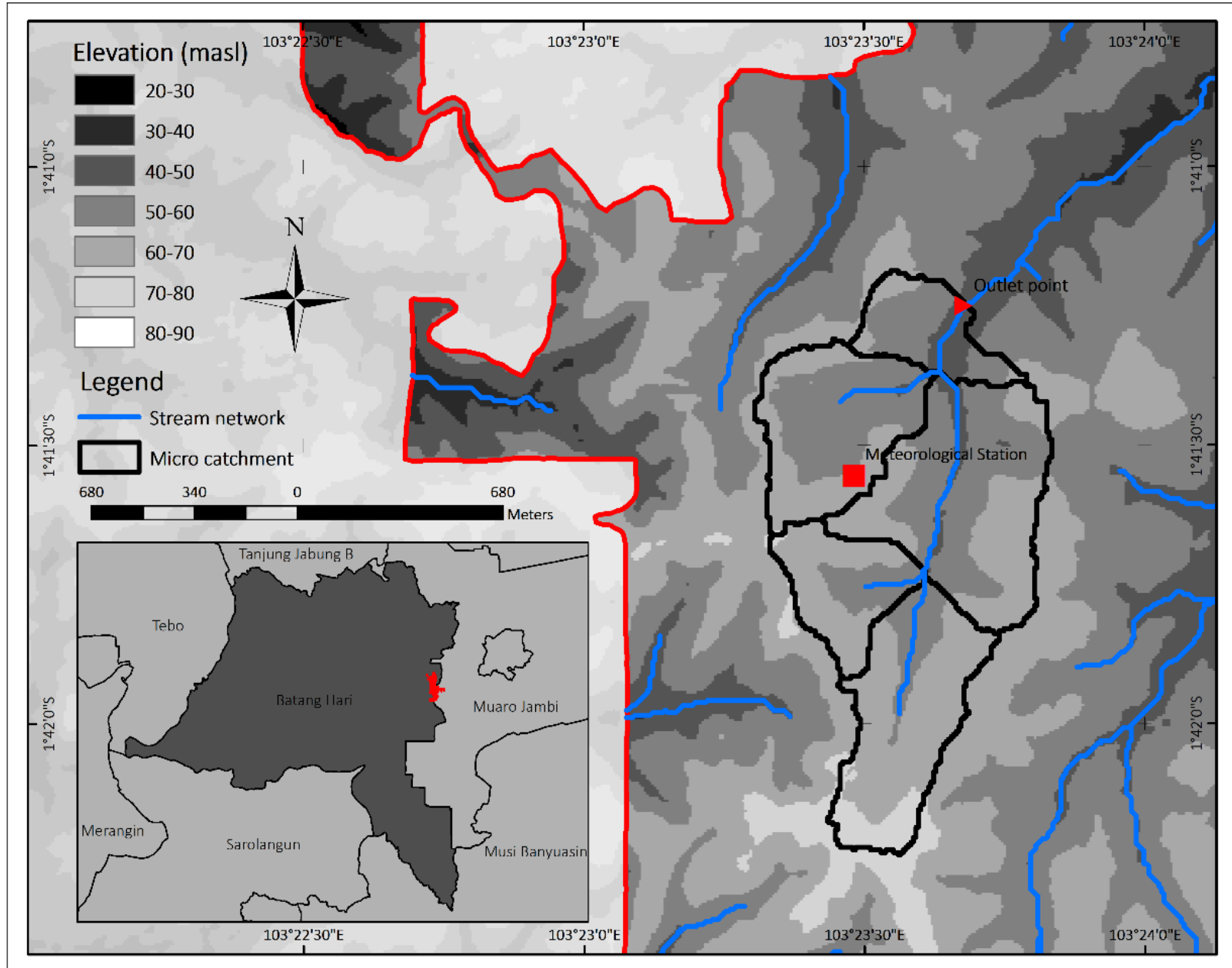

Figure 1. Study area: micro catchment located in Bajubang District, Batanghari Regency, Jambi Province 
flow approaches zero if there is no rain. The average annual air temperature is around $26.4^{\circ} \mathrm{C}$, and the annual rainfall is $3300 \mathrm{~mm}$. The study area has only one type of soil, Acrisol, based on the FAO system, or Association of Typic Dystrudepts and Typic Hapludox based on the soil mapping unit system. Micro catchment with a highly controlled environment of one soil type and one land cover type make water regulation services estimation from the SCS-CN method easier to examine than highly heterogeneous areas.

A quality-controlled automatic water level recorder (AWLR) was installed at the outlet basin, and a meteorological station was installed in the center of the micro catchment to support the SWAT model simulation. The Collaborative Research Center's (CRC990) meteorological observation station is designed to take representative biophysical measurements on oil palm plantation on very detailed temporal scales ranging from hourly to daily. Meteorological measurements were carried out from March 2014 to November 2019 for model simulation, while river discharge measurements were carried out from September 2017 to February 2018 for model calibration and validation. Because there are missing observation data at times, we also use Climate Forecast System Reanalysis (CFSR) data from the SWAT Global Weather Generator Database to fill in missing data during the simulation.

\section{Water Regulation Services Simulation Using Soil and Water Assessment Tools (SWAT)}

Soil and Water Assessment Tools (SWAT) is a computationally efficient physical model developed by J. G. Arnold (Arnold et al., 1998) for the USDA Agriculture Research Service (USDA-ARS) from several ARS (Agricultural Research Service) models (Neitsch et al., 2015). SWAT works at a watershed scale and allows several different physical processes to be simulated in a watershed for long-term periods, such as the hydrological cycle, plant growth, pesticide cycle, and nutrient cycle (Neitsch et al., 2015; Zhang et al., 2019). SWAT is a semi-distributed model that divides a watershed into several sub-basin and then divides each sub-basin into several hydrological response units (HRUs). The sub-basin and HRU are used to explain the spatial heterogeneity of the physical processes in the watershed system for each combination of land use features, vegetation, soil, and topography (Zhang et al., 2019). Also, sub-basin and HRU help increase simulations' accuracy because heterogeneity in land use, soil types, and topography have different impacts on physical processes (Wang et al., 2019)

The output of the SWAT model can help stakeholders in assessing the impact of land management on water quantity and quality, nutrient leaching, and sediment transport, especially for complex watersheds with features that vary spatially and temporally but have limited data availability due to lack of monitoring data (Arnold et al., 1998; Dash et al., 2020). No matter what type of problem is studied with SWAT, hydrological processes are the driving force behind everything in the watershed system. The main hydrological processes simulated with the SWAT model include evapo-transpiration, surface flow, lateral flow, and baseflow, calculated based on the water balance equation (Zhang et al., 2019).

$S W_{t}=S W_{0}+\sum_{i=1}^{t}\left(P-Q_{S R O}-E_{a}-Q_{S S R O}-Q_{B R O}\right.$

where $S W_{t}$ is the final condition of soil moisture, $S_{W}$ is the initial condition of soil moisture, $\mathrm{P}$ is precipitation, $Q_{S R O}$ is surface runoff, $E_{a}$ is actual evapotranspiration, $\mathrm{Q}_{\text {sSRo }}$ is a lateral flow, $\mathrm{Q}_{\mathrm{BFO}}$ is base flow, $\mathrm{t}$ is time in days, all units are in the metric system ( $\mathrm{mm}$ ).

Pre-processing, model running, analysis of sensitivity, and accuracy and uncertainty test are the four stages of the SWAT simulation. Spatial data needed to run SWAT model are digital elevation model (DEM) from Geospatial Information Agency which is available with a spatial resolution of 8 meters, land cover derived from Landsat-8 OLI interpretation with 30 meters spatial resolution, soil map with scale 1: 50,000 from Indonesian Center for Agricultural Land Resources Research and Development, land cover and soil physics attribute from the field survey, and daily meteorological observation data.

\section{a. Pre-processing}

Micro catchment and stream network delineation from DEM data and HRU definition from land cover, soil type, and slope data are all part of the pre-processing stage. A threshold of 100 hectares area was applied when extracting the watershed boundary and river network from the DEM data, resulting in a 1.14 $\mathrm{km} 2$ micro catchment divided into five sub-watersheds. The HRU is defined from one land cover type, one soil type, and five slope classes, resulting in a total of 22 HRUs for the entire micro catchment or 1-5 HRU(s) in each sub-watershed depending on slope heterogeneity Pre-processing also includes database input, including land cover and management (.mgt), soil-water properties (.sol), daily precipitation (.pcp), and daily potential evapotranspiration (.pet). Soil-water properties required for the SWAT simulation include bulk density, porosity, permeability, texture, organic matter content, and available water content. The PET method in the SWAT model chosen in this study is Penman-Monteith, which is calculated based on the equation below:

$P E T=\frac{1000 \times\left(\Delta \times\left(R_{n}-G\right)+\left(\rho_{a} \times c_{p} \times \frac{\left(e_{S}-e_{a}\right)}{r_{a}}\right)\right)}{\left(\Delta+\left(\gamma \times\left(1+\frac{r_{c}}{r_{a}}\right)\right)\right) \times \rho_{W} \times L}$ 
where PET is daily potential evapotranspiration $(\mathrm{mm})$, 1000 is conversion meter to the millimeter, $\Delta$ is the slope of the water vapor pressure to temperature $\left(\mathrm{kPa} /{ }^{\circ} \mathrm{C}\right), \mathrm{R}_{\mathrm{n}}$ is daily net radiation $\left(\mathrm{MJ} / \mathrm{m}^{2}\right), \mathrm{G}$ is daily ground heat flux $\left(\mathrm{MJ} / \mathrm{m}^{2}\right), v$ is psychrometric constant $\left(\mathrm{kPa} /{ }^{\circ} \mathrm{C}\right), \rho_{a}$ is the air density $\left(\mathrm{kg} / \mathrm{m}^{3}\right), \rho_{\mathrm{w}}$ is water density $\left(\mathrm{kg} / \mathrm{m}^{3}\right), L$ is the latent heat of water vaporization $(\mathrm{MJ} / \mathrm{kg}), r_{c}$ is canopy resistance $(\mathrm{s} / \mathrm{m}), r_{\mathrm{a}}$ is aerodynamic resistance $(\mathrm{s} / \mathrm{m}), \mathrm{e}_{\mathrm{s}}$ is saturation vapor pressure $(\mathrm{kPa}), \mathrm{e}_{a}$ is actual vapor pressure $(\mathrm{kPa})$, and $\mathrm{c}_{\mathrm{p}}$ is the specific heat at constant pressure $\left(\mathrm{MJ} / \mathrm{kg}^{\circ} \mathrm{C}\right)$. Although observation weather data is available to calculate PET manually, the PET calculation in the above equation is executed by the SWAT model structure, which requires input data in the form of maximum and minimum air temperature (.tmp), solar radiation (.slr), wind speed (.wnd), and relative humidity (.rhu).

\section{b. SWAT Simulation using CN-SM and CN-ET Approach}

Hydrological modeling using SWAT goes through two processes: simulation of the hydrology process of each HRU and flow routing from HRU to sub-basin outlet through the stream network (Gao et al., 2018). This study aims to compare the two SCS-CN approaches so that the rainfall-runoff transformation in each HRU is modeled by the SCS-CN method (Eq. 3). The SCS-CN method is a simple rainfall-runoff transformation method that only requires daily rainfall data (P) and watershed $\mathrm{CN}$ data but powerful to estimate excess rainfall as surface runoff (Hawkins et al., 2019).

$Q_{S R O}={\frac{\left(P-I_{a}\right)^{2}}{\left(P-I_{a}+S\right)}}^{2}$

where $Q_{S R O}$ is daily surface runoff accumulation $(\mathrm{mm})$, $\mathrm{P}$ is daily precipitation $(\mathrm{mm}), \mathrm{S}$ is retention parameter $(\mathrm{mm})$, and $\mathrm{I}_{\mathrm{a}}$ is an initial abstraction $(\mathrm{mm})$. The three main processes considered in initial abstraction are rainfall interception, storage depression, and infiltration before the surface runoff. Initial abstraction is generally assumed 0.2 of the retention parameter, and QsRo only occurs when $P>I_{a}\left(Q_{S R O}=0\right.$ if $\left.P \leq I_{a}\right)$. The retention parameter $(\mathrm{S})$ can be approx-imated as a function of the $\mathrm{CN}$, according to $\mathrm{Eq} 4$. The $\mathrm{CN}$ value varies spatially due to differences in land cover, soil type, and land management.

$S=254\left(\frac{100}{C N}-1\right)$

In a temporally continuous model, such as SWAT, the $\mathrm{CN}$ value will also vary temporally by considering the antecedent moisture condition (AMC). SCS defines three AMC, CN1-dry (wilting point), CN2-average moisture, and CN3-wet (field capacity). The CN2 value for oil palm land with Acrisol soil type (HSG C-low infiltration rate then thoroughly wetted) was taken from the reference table, while $\mathrm{CN} 1$ and $\mathrm{CN} 3$ were calculated from CN2, Eq. 5 for CN1 and Eq. 6 for CN3 (Neitsch et al., 2015).

$$
\begin{aligned}
& C N_{1}=C N_{2}-\frac{20 \times\left(100-C N_{2}\right)}{\left(100-C N_{2}+\exp \left[2.533-0.0636 \times\left(100-C N_{2}\right)\right]\right)} \\
& C N_{3}=C N_{2} \times \exp \left[0.00673 \times\left(100-C N_{2}\right)\right]
\end{aligned}
$$

If the slope factor is adjusted in the $\mathrm{CN}$ calculation (Ajmal et al., 2020), the $\mathrm{CN}_{2}$ value will also vary spatially according to the slope variations based on Eq. 7 (Neitsch et al., 2015). The $\mathrm{CN}_{2}$ value given by the reference table is the default $\mathrm{CN}_{2}$ value at a $5 \%$ slope.

$$
\begin{aligned}
& C N_{2 s}=\left(\frac{\left(C N_{3}-C N_{2}\right)}{3} \times[1-2 \exp (-13.86 \times \text { slope })]\right)+ \\
& \mathrm{CN}_{2}
\end{aligned}
$$

The SWAT model used in this study, the 2012 SWAT version, has two approaches in calculating the temporal variation of retention parameters, $\mathrm{CN}-\mathrm{SM}$ and $\mathrm{CN}-\mathrm{ET}$. CN-SM is the original procedure in the SCS-CN method and has been used in several hydrological models for long-term simulations. If CN-SM is selected, the combination of $\mathrm{CN}$ and soil moisture (SM) is used to estimate surface runoff from rainfall so that the daily retention parameter value will vary with daily $\mathrm{CN}$ and SM variations.

$S=S_{\text {max }} \times\left(1-\frac{S W}{\left[S W+\exp \left(w_{1}-w_{2} \times S W\right)\right]}\right)$

where $S$ is the daily retention parameter $(\mathrm{mm}), \mathrm{Smax}$ is the maximum retention parameter that derived from Eq 4 using $\mathrm{CN}_{1}(\mathrm{~mm}), \mathrm{SM}$ is soil moisture excluding the amount of water retained at the wilting point $\left(\mathrm{mm} \mathrm{H}_{2} \mathrm{O}\right)$ $\mathrm{w}_{1}$ is the first shape coefficient, and $\mathrm{w}_{2}$ is second shape coefficient. The first and second shape coefficient is a function of the soil moisture in the field capacity $(\mathrm{mm}$ $\mathrm{H}_{2} \mathrm{O}$ ), soil moisture at saturated condition $\left(\mathrm{mm} \mathrm{H}_{2} \mathrm{O}\right)$, retention parameters at $\mathrm{CN}_{3}$ condition $\left(\mathrm{S}_{3}\right)$, retention parameters at $\mathrm{CN}_{1}$ condition $\left(\mathrm{S}_{\max }\right)$, and retention parameters at value $\mathrm{CN}$ of $99(\mathrm{~S}=2.54 \mathrm{~mm}$ ) (Neitsch et al., 2015).

On the other hand, if CN-ET is chosen for calculation, the retention parameter value is a function of PET so that the value does not depend on SM but depends on previous climatic conditions. This approach is highly dependent on PET calculations, so the choice of the PET method, whether Penman-Monteith, Thornthwaite, or so on, will affect the estimation of surface runoff (Kannan et al., 2008). CN-ET is designed to deplete $S$ values faster when the soil is saturated but slower when it is in dry condition. During rain, the retention parameter is calculated as the sum of the previous retention parameters value $\left(S_{\text {prev }}\right)$ and the current PET that corrected by $S_{\text {prev, }}$ depletion coefficient (cncoef), and $\mathrm{S}_{\max }$ and reduced by infiltrated rainfall ( $\mathrm{P}$ $\left.Q_{s R O}\right)$. The initial retention parameter value at the first 
time of measurement (there is no $S_{\text {prev }}$ value) is given $0.9 \times \mathrm{S}_{\max }$

$S=S_{\text {prev }}+\left(\exp \left(\frac{- \text { cncoef } \times S_{\text {prev }}}{S_{\max }}\right)\right)-\left(P-Q_{S R O}\right)$

\section{c. Sensitivity Analysis}

Sensitivity analysis is an analysis conducted to determine the model output's response in input parameters changes for a particular area. The sensitivity analysis is grouped into local sensitivity, and global sensitivity approaches. The local sensitivity approach determines the output response to variations in one input parameter value where the other parameters' value is considered constant. Therefore, this approach does not pay attention to the interaction between input parameters in estimating output. On the other hand, the global sensitivity approach explores the entire input parameter range and then varied simultaneously to investigate the output responses on parameter interaction. Input-output pairs are sampled using the Latin Hypercube Sampling (LHS) technique to map their interaction and measure the uncertainty of output caused by each parameter combination. Then, to determine whether a parameter is significantly sensitive or not for a particular region, t-test statistics are used to identify each parameter's relative significance to the output.

\section{d. Calibration, Validation, and Uncertainty Test}

Simulations were carried out from 2014 to 2019, wherein the first-year simulation, 2014, was used for warming up the model. However, climate data is missing for one year, from August 2016 to July 2017, so we used weather generator (WGN) data to generate the climate data. The weather generator database is obtained from the Climate Forecast System Reanalysis (CFSR) and can be downloaded at swat.tamu.edu/data. Like other studies, the parameter calibration and validation in this study were based on streamflow simulations. Utilization of soil moisture or actual evapotranspiration, which is part of water regulation services, is rarely used for calibration and validation (Karlberg and Dile, 2016). It is because streamflow tends to be easily measured directly, more costeffective, and easier to obtain temporal data than soil moisture and actual evapotranspiration measurement. Daily observation streamflow data from 28 September 2017 to 25 February 2018 (150 days) were used for the calibration and validation process. The first 75 streamflow data were used for the calibration process, and the last 75 data were used for validation. Compared to manual calibration, which is time-consuming and fails to identify parameter sensitivity, this study uses automatic calibration based on the Sequential
Uncertainty Fitting-2 (SUFI-2) algorithm using SWATCUP software (Abbaspour, 2015).

Based on the literature review, 21 parameters and their respective ranges were selected for model calibration to capture the main hydrological processes. The 20 parameters are calibrated on the CN-SM approaches, CN2 (curve number in average moisture conditions), SOL_K (soil permeability), SOL_BD (bulk density), SOL_AWC (available water content), SOL_CBN (soil organic matter content), OV_N (manning overland flow), CH_N2 (manning coefficient of the main channel), $\mathrm{CH}_{-} \mathrm{K} 2$ (hydraulic conductivity of the main channel), CANMX (canopy storage maximum), LAT_TTIME (lateral flow travel time), ALPHA_BF (baseflow recession constant), GWQMN (water level threshold for base flow), REVAPMN (water level threshold for "revap"), GW_DELAY (delay time for aquifer recharge), ESCO (soil evaporation compensation coefficient), and EPCO (plant uptake compensation factor), ALPHA_BNK (bank flow recession constant), SOL_Z (soil depth), RCHRG_DP (percolation coefficient), and $\mathrm{CH}_{-} \mathrm{N} 1$ (manning coefficient of the tributary channel). The same parameters are used for the CN-ET calibration; also, CN-ET adds CNCOEF (CN depletion coefficient) to be calibrated.

To assess the model performance, the model is statistically measured based on NSE (Nash-Sutcliffe Efficiency) and $\mathrm{R}^{2}$. NSE is a statistical indicator that has been widely used so far for hydrological calibration and validation. NSE value ranges from $-\infty$, which indicates the model is inaccurate, to 1 , which indicates that the model is very accurate.

$N S E=1-\left[\frac{\sum_{i=1}^{n}\left(Y_{i}^{\text {obs }}-Y_{i}^{\text {sim }}\right)^{2}}{\sum_{i=1}^{n}\left(Y_{i}^{\text {obs }}-Y_{i}^{\text {mean }}\right)^{2}}\right]$

where $Y_{\text {obs }}$ is observation data, $Y_{\text {sim }}$ is simulation data, and $Y_{\text {mean }}$ is the average observation data. Other statistical criteria used was the coefficient of determination $\left(R^{2}\right) . R^{2}$ value ranges from 0 , indicating that the model is inaccurate to 1 , which indicates that the model is very accurate.

$R^{2}=\left[\frac{\sum_{i=1}^{n}\left(O \mathrm{Obs}_{i}-\overline{\mathrm{Obs}}\right)\left(\mathrm{Sim}_{i}-\overline{\mathrm{Slm}}\right)}{\sqrt{\left.\sum_{i=1}^{n}(\mathrm{Obs})_{i}-\overline{\mathrm{Obs}}\right)^{2}} \sqrt{\sum_{i=1}^{n}\left(\mathrm{Sim}_{i}-\overline{\mathrm{Slm}}\right)^{2}}}\right]^{2}$

where Obs is observed data, and Sim is simulated data. There are no absolute criteria for assessing a hydrological model's performance outlined in the literatures. However, some criteria are suggested including the NSE criteria proposed by Moriasi et al., (2007) and the $\mathrm{R}^{2}$ criteria by Ayele et al., (2017). 
Table 1. The statistical criteria for model performance.

\begin{tabular}{ccc}
\hline $\begin{array}{c}\text { NSE Value } \\
\text { (Moriasi et al., } \\
\text { 2007) }\end{array}$ & $\begin{array}{c}\mathbf{R}^{\mathbf{2}} \text { Value } \\
\text { (Ayele et al., } \\
2017)\end{array}$ & Criteria \\
\hline $0.75<$ NSE $<1.00$ & $0.7<\mathrm{R}^{2}<1$ & Very good \\
$0.65<\mathrm{NSE}<0.75$ & $0.6<\mathrm{R}^{2}<0.7$ & Good \\
$0.5<\mathrm{NSE}<0.65$ & $0.5<\mathrm{R}^{2}<0.6$ & Satisfactory \\
NSE $<0.5$ & $\mathrm{R}^{2}<0.5$ & Less Satisfactory \\
\hline
\end{tabular}

Comparison of CN-ET and CN-SM only using $\mathrm{R}^{2}$ and NSE was generally insufficient to measure structural uncertainty in the model. Therefore, the SUFI-2 algorithm in SWAT-CUP introduces the other statistical indicators to investigate the structural un-certainty associated with model simulation. The uncertainty of the calibration process is measured by the P-factor, which is the percentage of observed data that falls within the $95 \%$ prediction uncertainty between the 2.5 and 97.5 percentile (95PPU), and the R-factor, which indicates the mean thickness of 95PPU divided by the standard deviation of the observed data.

\section{RESULTS AND DISCUSSIONS}

\section{Sensitivity Analysis}

Sensitive parameters were defined as parameters that can affect the simulation performance, and their changes can significantly change the model output. On the other hand, changes in less sensitive parameters do not cause significant changes in the model output. Analysis of sensitivity is necessary because it provides information on which hydrological processes are most important in the study area and helps reduce the number of parameters in future studies by eliminating parameters identified as insensitive (Abbaspour et al., 2018). Table 2 provides global sensitivity rankings for $\mathrm{CN}-\mathrm{SM}$ and $\mathrm{CN}-\mathrm{ET}$, where the first rank is the most sensitive parameter, and the last rank is the least sensitive parameter. The sensitivity analysis results in this study, especially for CN-SM, are different from Tarigan et al., (2020; 2018), although research is carried out in the same landscape and provided similar outputs. Because SWAT has a complex structure, various possibilities and differences in parameter values and sensitivity will appear in the simulation to produce the similar result. The difference in sensitivity analysis is based on three things: the difference in location, the difference in the range of parameter values, and the difference in the number of calibrated parameters. As a part of the same macro watershed system, each sub-basin or micro catchment has different characteristics, so that the parameter sensitivity will vary according to these characteristics. Furthermore, the differences in the number of parameters and their upper-lower bound ranges selected in the calibration process also affect the sensitivity analysis. Therefore, we cannot directly apply sensitivity analysis results for one case study to another case study.

Table 2. The rank of the most sensitive parameter to least sensitive obtained during sensitivity analysis.

\begin{tabular}{|c|c|c|c|c|c|c|c|}
\hline \multicolumn{4}{|c|}{ CN-SM } & \multicolumn{4}{|c|}{ CN-ET } \\
\hline Rank & Parameter & t-test & p-value & Rank & Parameter & t-test & p-value \\
\hline 1 & $\mathrm{CN} 2^{\mathrm{a}}$ & 44.538 & $0.000^{\star \star}$ & 1 & $\mathrm{CN} 2^{\mathrm{a}}$ & 24.840 & $0.000^{* *}$ \\
\hline 2 & ALPHA_BNK ${ }^{a}$ & 26.301 & $0.000^{\star *}$ & 2 & ALPHA_BNK ${ }^{a}$ & 18.010 & 0.000 ** \\
\hline 3 & $\mathrm{CH}_{-} \mathrm{K} 2^{\mathrm{a}}$ & -21.523 & $0.000^{\star *}$ & 3 & $\mathrm{CH}_{-} \mathrm{K} 2^{\mathrm{a}}$ & -15.372 & 0.000 ** \\
\hline 4 & SOL_Z ${ }^{a}$ & 8.233 & $0.000^{\star *}$ & 4 & $\mathrm{ESCO}^{\mathrm{a}}$ & -14.833 & 0.000 ** \\
\hline 5 & SOL_BD & -7.335 & $0.000 * *$ & 5 & SOL_Z ${ }^{a}$ & 11.055 & 0.000 ** \\
\hline 6 & $\mathrm{ESCO}^{\mathrm{a}}$ & 6.011 & $0.000 * *$ & 6 & CNCOEF & 10.964 & 0.000 ** \\
\hline 7 & RCHRG_DPa & 4.852 & $0.000^{\star *}$ & 7 & $\mathrm{CH}_{-} \mathrm{N}^{\mathrm{a}}$ & -3.603 & 0.000 ** \\
\hline 8 & GWQMN & -3.799 & $0.000 * *$ & 8 & RCHRG_DP a & 2.702 & $0.007^{* *}$ \\
\hline 9 & $\mathrm{CH}_{-} \mathrm{N}{ }^{\mathrm{a}}$ & -3.755 & $0.000 * *$ & 9 & SOL_AWC & 2.634 & $0.009 * *$ \\
\hline 10 & OV_N & -1.633 & 0.103 & 10 & GWQMN & -2.598 & 0.010 \\
\hline 11 & SOL_AWC & -1.544 & 0.123 & 11 & CANMX & -2.263 & 0.024 \\
\hline 12 & EPCO & -1.362 & 0.174 & 12 & SOL_BD & -1.497 & 0.135 \\
\hline 13 & GW_DELAY & -1.249 & 0.212 & 13 & SOL_K & -1.376 & 0.169 \\
\hline 14 & ALPHA_BF & 1.227 & 0.220 & 14 & GW_DELAY & -1.101 & 0.271 \\
\hline 15 & LAT_TTIME & -1.178 & 0.239 & 15 & SOL_CBN & 1.005 & 0.315 \\
\hline 16 & CANMX & -0.977 & 0.329 & 16 & OV_N & -0.675 & 0.500 \\
\hline 17 & SOL_K & -0.551 & 0.582 & 17 & $\mathrm{CH} \_\mathrm{N} 1$ & 0.615 & 0.539 \\
\hline 18 & REVAPMN & -0.269 & 0.788 & 18 & LAT_TTIME & 0.404 & 0.686 \\
\hline 19 & SOL_CBN & -0.233 & 0.816 & 19 & ALPHA_BF & 0.293 & 0.769 \\
\hline \multirow[t]{2}{*}{20} & $\mathrm{CH} \_\mathrm{N} 1$ & 0.023 & 0.982 & 20 & EPCO & -0.236 & 0.813 \\
\hline & & & & 21 & REVAPMN & -0.018 & 0.986 \\
\hline
\end{tabular}

Note: ${ }^{\text {a }}$ parameters are sensitive in both approaches

** significant in $99 \%$ confidence interval ( $p$-value $<0,01)$ 
The SUFI-2 algorithm uses the Latin Hypercube Sampling (LHS) on global sensitivity analysis to determine which parameters are the most sensitive and less sensitive to the model's output in the study area during the parameter estimation process. Out of the 20 calibrated parameters for $\mathrm{CN}-\mathrm{SM}$ and 21 parameters for $\mathrm{CN}-\mathrm{ET}$, nine parameters were sensitive for CN-SM and $C N-E T$, respectively, at the $99 \%$ significance level. $\mathrm{CN} 2$, ALPHA_BNK, CH_K2, ESCO, SOL_Z, CH_N2, and RCHRG_DP are seven sensitive parameters for both approaches, indicated by $p$-value $<0.01$ and $\mid$ t-test $\mid>$ $\mathrm{t} \alpha=99 \%$, df. SOL_BD and GWQMN is a sensitive parameter for CN-SM but less sensitive for CN-ET. Besides that, SOL_AWC are the sensitive parameters for $\mathrm{CN}$-ET but less sensitive for CN-SM. CNCOEF, which is the only parameter in $\mathrm{CN}-\mathrm{ET}$, is also sensitive to the $\mathrm{CN}$ ET output. The remaining parameters are less sensitive, such as ALPHA_BF in either CN-ET or CN-SM, a sensitive parameter often found in the other studies but less sensitive in this study.

The results showed that the parameters equally sensitive for $\mathrm{CN}-\mathrm{ET}$ and $\mathrm{CN}-\mathrm{SM}$ have their respective essential roles in determining the streamflow output. The parameters rank in Table 2 indicates that CN2 is the most sensitive parameter for $\mathrm{CN}-\mathrm{ET}$ and $\mathrm{CN}-\mathrm{SM}$, as evidenced by the highest absolute t-test. It means that surface runoff generation is the primary hydrological process in the study area. It implies that streamflow variations are strongly influenced by the curve number justification as the main parameter in generating surface runoff that dominates streamflow. Various studies have shown that CN2 is the most sensitive parameter in surface runoff generation for the SCS-CN method. Theoretically, CN2 has a range of $0-100$, but in practice, CN2 has a range of 25-98, where the greater the value of $\mathrm{CN} 2$ implies an increase in surface runoff. It should also be noticed that CN2 is not the only sensitive parameter regarding surface runoff for $\mathrm{CN}-\mathrm{ET}$, but that CNCOEF also contributes substantially to surface runoff. CNCOEF has a range of $0-2$, but a range of 0.5-1.5 is sufficient to capture most of the watershed surface runoff trend. As with CN2, the increase in CNCOEF has implications for increased surface runoff.

Three parameters related to flow routing, ALPHA_BNK, $\mathrm{CH}_{-} \mathrm{N} 2$, and $\mathrm{CH}_{-} \mathrm{K} 2$, are included in the streamflow's sensitive parameters. Sensitive $\mathrm{CH}_{-} \mathrm{K} 2$ shows that the amount of streamflow is influenced by river-groundwater interaction in two directions. The river receives water from the groundwater in the high groundwater level (rainy season) and loses water to the groundwater through transmission loss in the low groundwater level (dry season). This interaction is closely related to the magnitude of channel hydraulic conductivity $\left(\mathrm{CH}_{-} \mathrm{K} 2\right)$ in the layer between rivers and groundwater. Furthermore, two-way interaction mainly occurs in intermittent rivers, and that reason causes $\mathrm{CH}_{-} \mathrm{N} 2$ to be a sensitive parameter in the study area. Sensitive parameters also occur in $\mathrm{CH}_{-} \mathrm{N} 2$, where based on Manning's equation, streamflow velocity is a function of the hydraulic radius, river slope, and riverbed roughness expressed by the manning coefficient ( $\left.\mathrm{CH}_{-} \mathrm{N} 2\right)$. The higher $\mathrm{CH}_{-} \mathrm{N} 2$ value indicates a very rough riverbed and implies lower streamflow, vice versa. The sensitivity of ALPHA_BNK shows that the volume of water from bank storage also contributes significantly to streamflow. Riverbank storage is volume water stored at the riverbed or riverbank during high groundwater level periods and then returned to the river during low groundwater level periods. This riverbank storage will dominate the intermittent streamflow during the dry season, in contrast to the permanent river dominated by baseflow. The increase in ALPHA_BNK has implications in increasing water volume added from bank storage into rivers (Neitsch et al., 2015).

Three other parameters that are equally sensitive for CN-ET and CM are SOL_Z, ESCO, and RCHRG_DP. SOL_Z or soil depth from the surface to the parent material layer, with SOL_BD (in CN-SM) and SOL_AWC (in CN-SM), implies soil water dynamics and runoff distribution to streamflow. Deep soils (higher SOL_Z) imply higher soil water storage than shallow soil (lower SOL_Z) though it is in the same \%v/v soil moisture condition. ESCO is a parameter that affects the runoff component by controlling the range of soil depth to meet soil evaporation demand. ESCO has a range of $0-1$, where the decrease in ESCO allows the deeper soil layers to compensate for water deficit in the topsoil through the effect of capillary water movement. The lower the ESCO value leads to higher soil evapotranspiration and vice versa. The last sensitive parameter is RCHRG_DP, the fraction of percolation from the root zone to fill deep aquifers. RCHRG DP has a range of 0 to 1 , and lowering it reduces the fraction of percolation that fills deep aquifers. Percolated soil water replenishes more shallow aquifers in this situation, implying an increase in baseflow (Zanin et al., 2018).

\section{Calibration and Validation using Streamflow Data}

The objectives to be solved, the available input data, the complexity of the model, and the reliability and uncertainty of the model are things that need to be considered in choosing a hydrological model. Some structural uncertainties affect the output value in a SWAT simulation: conceptual model's simplification, input data variation, and parameter values justification (Abbaspour et al., 2018). The parameter uncertainty can 
Table 3. Performance of the $\mathrm{CN}-\mathrm{SM}$ and $\mathrm{CN}-\mathrm{ET}$ calibration and validation.

\begin{tabular}{|c|c|c|c|c|c|c|c|c|}
\hline \multirow{2}{*}{ Criteria } & \multicolumn{4}{|c|}{ Calibration } & \multicolumn{4}{|c|}{ Validation } \\
\hline & P-Factor ${ }^{a}$ & R-Factor ${ }^{a}$ & NSE & $R-s q^{b}$ & P-Factor ${ }^{a}$ & R-Factor ${ }^{a}$ & NSE & $R-s q^{b}$ \\
\hline CN-SM & 73\%"\# & $0.60^{\# \#}$ & $0.78^{* * * *}$ & $0.80^{* \star * *}$ & $83 \% \# \#$ & $0.65^{\# \#}$ & $0.79^{\star \star \star \star}$ & $0.81^{\star \star \star \star}$ \\
\hline CN-ET & 75\%"\#\# & $0.63^{\# \#}$ & $0.80^{* \star \star \star}$ & $0.83^{\star \star \star \star *}$ & $86 \%{ }^{\# \#}$ & $0.68^{\# \#}$ & $0.67^{\star \star \star}$ & $0.69^{* \star *}$ \\
\hline
\end{tabular}

Note: best values are presented in bold

a \#\# acceptable, \# not acceptable

$\mathrm{b} * * * *$ very good, ${ }^{* * *}$ good, ${ }^{* *}$ satisfactory, * less satisfactory

be in the form of (1) the same parameters combination in different approaches that may have different outputs, and (2) different parameters combination in the same approach can produce the same output. The parameters uncertainty arises because some of these parameters are difficult to measure so that it is difficult to get the absolute value. Therefore, automatic calibration with the SUFI-2 algorithm aims to minimize this uncertainty, where manual calibration cannot resolve it. As a stochastic approach, the SUFI-2 algorithm expresses the parameter uncertainty as a distribution, where the distribution will result in a very variable output probability (Abbaspour, 2015). SWAT simulation is defined as calibrated simulation when the best simulation from several iterations also has more than some percentage observation data enveloped by 95PPU apart from having a significant value of R2 or NSE. Besides that, the mean distance between the lowest and highest 95PPU bound is less than the observation data's standard deviation.

According to Abbaspour (2015) the recommended 95PPU ( $\mathrm{P}$-factor) is more than $70 \%$, and the $\mathrm{R}$ factor less than 1. It will be better if the P-factor close to $100 \%$ and the R-factor close to 0 . However, to achieve a high $\mathrm{P}$-factor, it is necessary to sacrifice the $\mathrm{R}$-factor value and vice versa. Then, the best simulation is defined as a simulation with a balanced P-factor and $\mathrm{R}$-factor value when it achieves the highest NSE or R2 values. According to the 95PPU plot interpretation, the uncertainties that arise during $\mathrm{CN}-\mathrm{SM}$ and $\mathrm{CN}-\mathrm{ET}$ calibration are considered acceptable, as indicated by the $\mathrm{P}$-factor $>70 \%$ and $\mathrm{R}$-factor $<1$. It means that more

a.

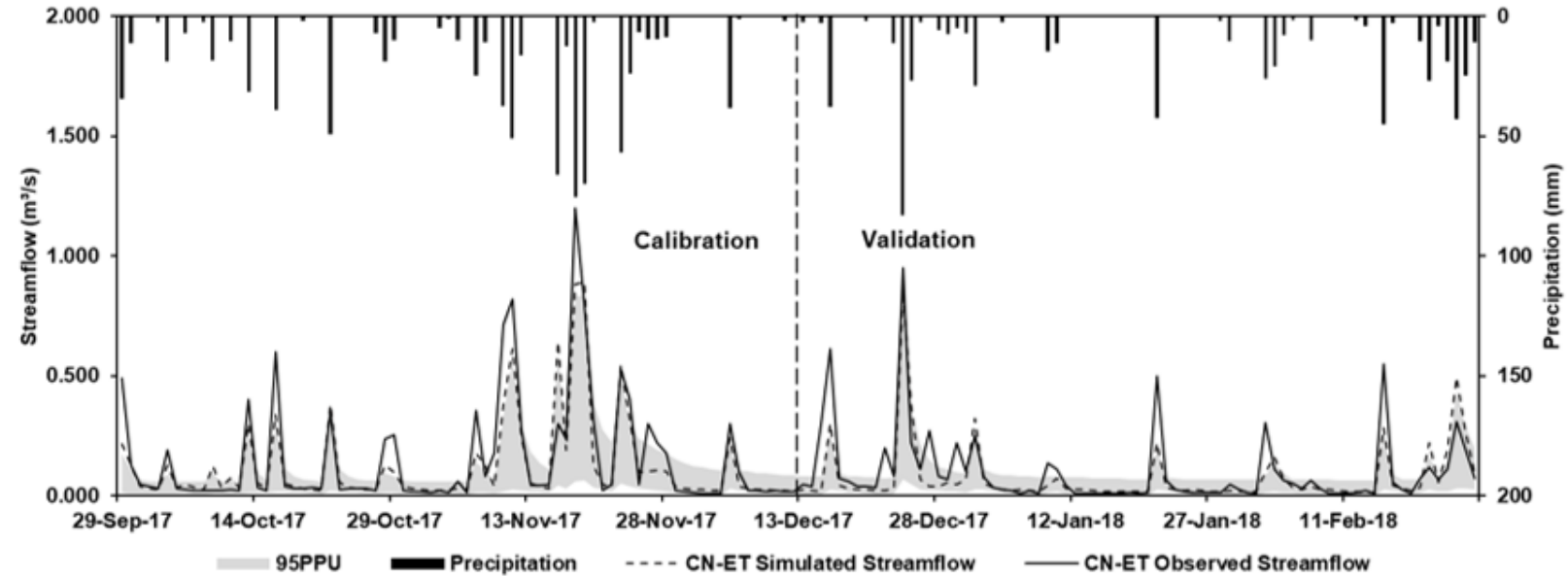

b.

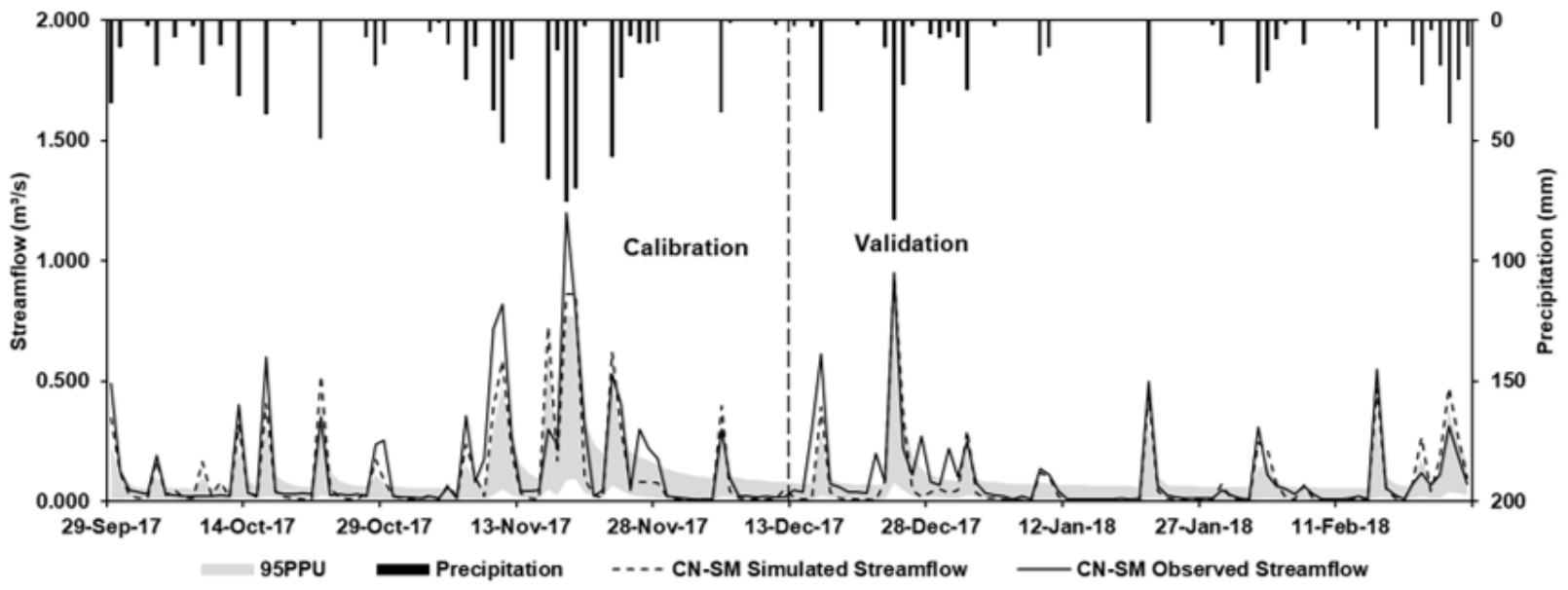

Figure 2. Calibrated and validated streamflow for (a) CN-ET approach and (b) CN-SM approach 


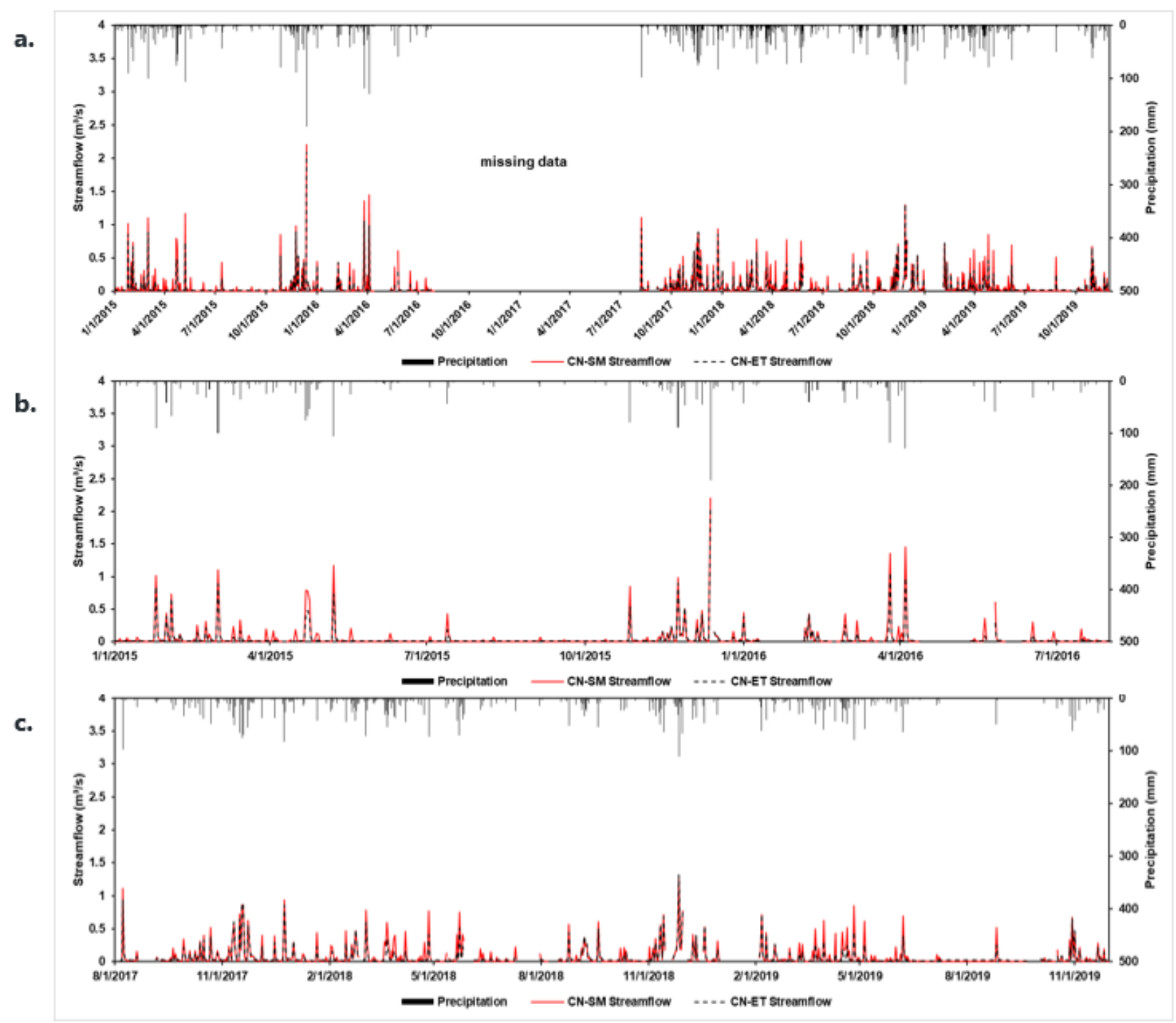

Figure 3. (a) CN-SM and CN-ET streamflow output during the 2015-2019 simulation period, (b) zoomed in for the 2015-2016 period (before missing data), (c) zoomed in for the 2017-2019 period (after missing data)

than 105 out of 150 observed streamflow data are in the 95PPU range. Although CN-ET has a slightly higher P-Factor than CN-SM, a narrower 95PPU range (RFactor) was obtained for CN-SM. In the same lower and upper bound ranges (Table 4), various combinations of CN-SM parameters during Latin Hypercube sampling result in less spread output, or the upper and lower 95PPU ranges are not as scattered as CN-ET. So, CN$\mathrm{SM}$ has good consistency in capturing parameters uncertainty than $\mathrm{CN}$-ET even though some observational data cannot be captured in that parameter range. This uncertainty test is carried out with many iterations; hence, the simulation uncertainty is not due to inadequate calibration but appears from the structural uncertainty behind $\mathrm{CN}-\mathrm{SM}$ and $\mathrm{CN}-\mathrm{ET}$ conceptual model to capture hydrological process dynamics (Zhang et al., 2019).
Aside from showing the uncertainty indicators, Table 3 also shows the statistical indicators commonly used to evaluate the model's reliability (NSE and $R^{2}$ ). The CN-SM and CN-ET performance reliability for estimating water regulation services in monoculture oil palm plantations was assessed based on calibrated and validated simulation results using daily observation streamflow data recorded by Automatic Water Level Recorder (AWLR). During the calibration period, CN-SM and $\mathrm{CN}$-ET are equally reliable in streamflow simulation, characterized by the NSE value $>0.75$ (Moriasi et al., 2007) and $R^{2}>0.70$ (Ayele et al., 2017). In this calibration period, CN-ET's performance higher than $\mathrm{CN}$-SM even though it was in the same category. In contrast, CN-SM R $\mathrm{R}^{2}$ and NSE still showed excellent category during the validation period; however, $\mathrm{CN}-\mathrm{ET}$ 
Table 4. Calibrated parameters with their range and best-fit values.

\begin{tabular}{|c|c|c|c|c|c|c|c|c|c|}
\hline \multirow[b]{2}{*}{ Categories } & \multirow{2}{*}{ Parameters $^{\mathrm{a}}$} & \multicolumn{2}{|c|}{ Range $^{b}$} & \multicolumn{3}{|c|}{ CN-SM } & \multicolumn{3}{|c|}{ CN-ET } \\
\hline & & LB & UB & Best fit & Init $^{\mathbf{c}}$ & $\mathrm{New}^{\mathrm{d}}$ & Best fit & Init $^{c}$ & New $^{d}$ \\
\hline \multirow{3}{*}{ Evapotranspiration } & $v_{-} E S C O$ & 0 & 1 & 0.949 & & & 0.255 & & \\
\hline & $V_{E} E P C O$ & 0 & 1 & 0.667 & & & 0.471 & & \\
\hline & V_CANMX & 0 & 10 & 2.45 & & & 7.79 & & \\
\hline \multirow{3}{*}{$\begin{array}{l}\text { Surface runoff for oil } \\
\text { palm with HSG C }\end{array}$} & $r_{-} \mathrm{CN} 2$ & -0.25 & 0.25 & 0.2325 & 77 & 94.9 & 0.2275 & 77 & 94.5 \\
\hline & $\mathrm{r}_{-} \mathrm{OV} \_\mathrm{N}$ & -0.2 & 0.2 & -0.11 & 0.14 & 0.126 & 0.007 & 0.14 & 0.141 \\
\hline & V_CNCOEF & 0 & 1 & - & & & 1.106 & & \\
\hline \multirow{5}{*}{$\begin{array}{l}\text { Soil characteristic for } \\
\text { Acrisol with oil palm } \\
\text { plantation }\end{array}$} & r_SOL_Z & -0.9 & 0.9 & 0.184 & 1000 & 1184.4 & -0.626 & 1000 & 374 \\
\hline & r_SOL_K & -0.2 & 0.2 & 0.044 & 75 & 78.33 & -0.0316 & 76.7 & 74.3 \\
\hline & r_SOL_AWC & -0.2 & 0.2 & -0.198 & 0.094 & 0.0754 & -0.153 & 0.094 & 0.0796 \\
\hline & r_SOL_CBN & -0.2 & 0.2 & -0.117 & 0.51 & 0.45 & 0.1572 & 0.51 & 0.59 \\
\hline & $r_{-}$SOL_BD & -0.2 & 0.2 & 0.188 & 1.38 & 1.64 & -0.187 & 1.38 & 1.122 \\
\hline Lateral flow & V_LAT_TTIME & 0 & 180 & 57 & & & 68.94 & & \\
\hline \multirow{5}{*}{ Groundwater } & V_ALPHA_BF & 0 & 1 & 0.981 & & & 0.681 & & \\
\hline & v_GWQMN & 0 & 5000 & 495 & & & 2545 & & \\
\hline & V_REVAPMN & 0 & 500 & 30.5 & & & 362.5 & & \\
\hline & V_GW_DELAY & 0 & 300 & 147.9 & & & 192.3 & & \\
\hline & V_RCHRG_DP & 0 & 1 & 0.925 & & & 0.953 & & \\
\hline \multirow[t]{4}{*}{ Routing } & V_CH_N1 & 0 & 0.3 & 0.2625 & & & 0.2643 & & \\
\hline & V_CH_N2 & 0 & 0.3 & 0.061 & & & 0.187 & & \\
\hline & v_ALPHA_BNK & 0 & 1 & 0.667 & & & 0.731 & & \\
\hline & V_CH_K2 & 0 & 500 & 5.5 & & & 26.5 & & \\
\hline
\end{tabular}

Note: ${ }^{a} v$ : replace the initial value with the best fit value, r: multiply the initial value with the (1+best fit value)

${ }^{b}$ LB: lower bound, UB: upper bound

c init: initial value before multiplying with best-fit parameter

${ }^{d}$ new: new value after multiplying with best-fit parameter

$\mathrm{R}^{2}<0.70$ and NSE $<0.75$, indicating CN-ET performance was slightly worse. Regardless of using statistical indicators, evaluation of the CN-ET and CN-SM approaches was also carried out by hydrograph interpretation. Com-parison between observed and the best streamflow simulation during the calibration and validation period for each $\mathrm{CN}$-ET and CN-SM with its uncertainty (95PPU) is shown in Figure 2.

The hydrograph in Figure 2 shows that both $\mathrm{CN}-\mathrm{ET}$ and CN-SM can simulate the temporal streamflow dynamics well. The original SCS-CN method, CN-SM, which was developed explicitly for surface runoff generation in micro watersheds dominated by agri-culture (Soulis, 2021), performed well in the study area. CN-SM has also been shown to be reliable in predicting peak runoff (Cheng et al., 2016), and the reliability of CN-SM for a similar region was also demonstrated by Tarigan et al., (2020; 2018). The mo- dified SCS-CN, CN-ET, could also perform well in the study area. A comparison of daily CN-ET and CN-SM streamflow during the 2015-2019 simulation period in Figure 3 shown that both outputs are almost identical with an $R^{2}$ of 0.91 . Based on Kannan et al., (2008), the excellent performance of $\mathrm{CN}-\mathrm{ET}$ in the surface runoff simulation

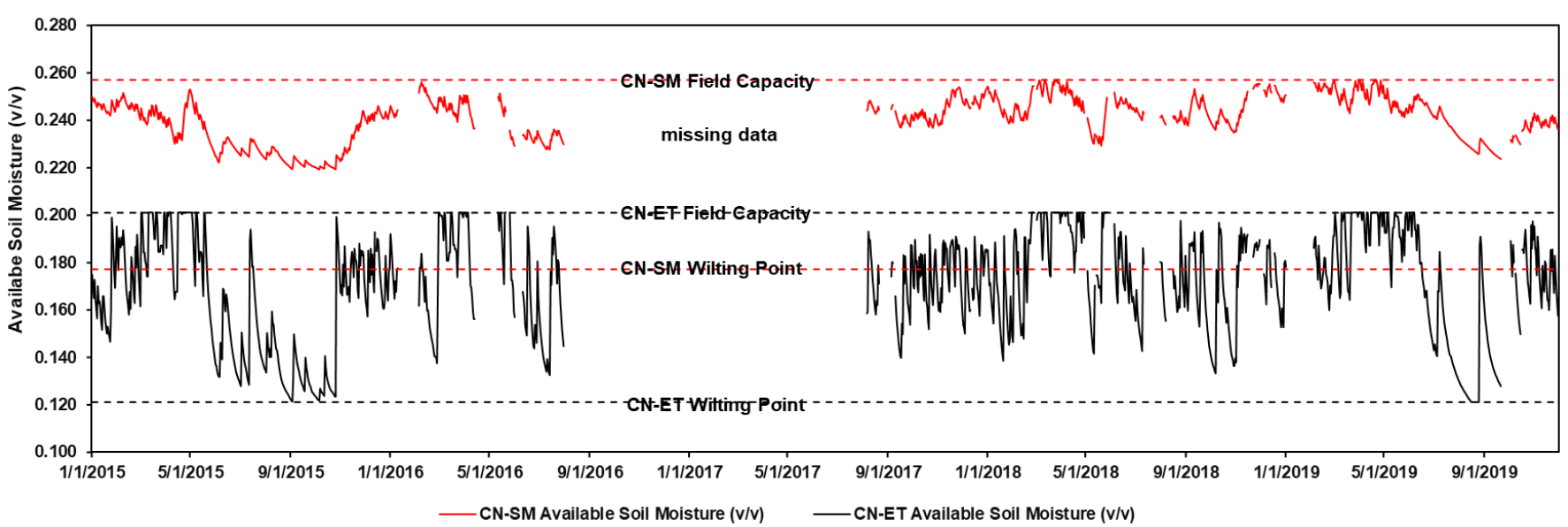

Figure 4. CN-SM and CN-ET soil moisture output during the 2015-2019 simulation period 


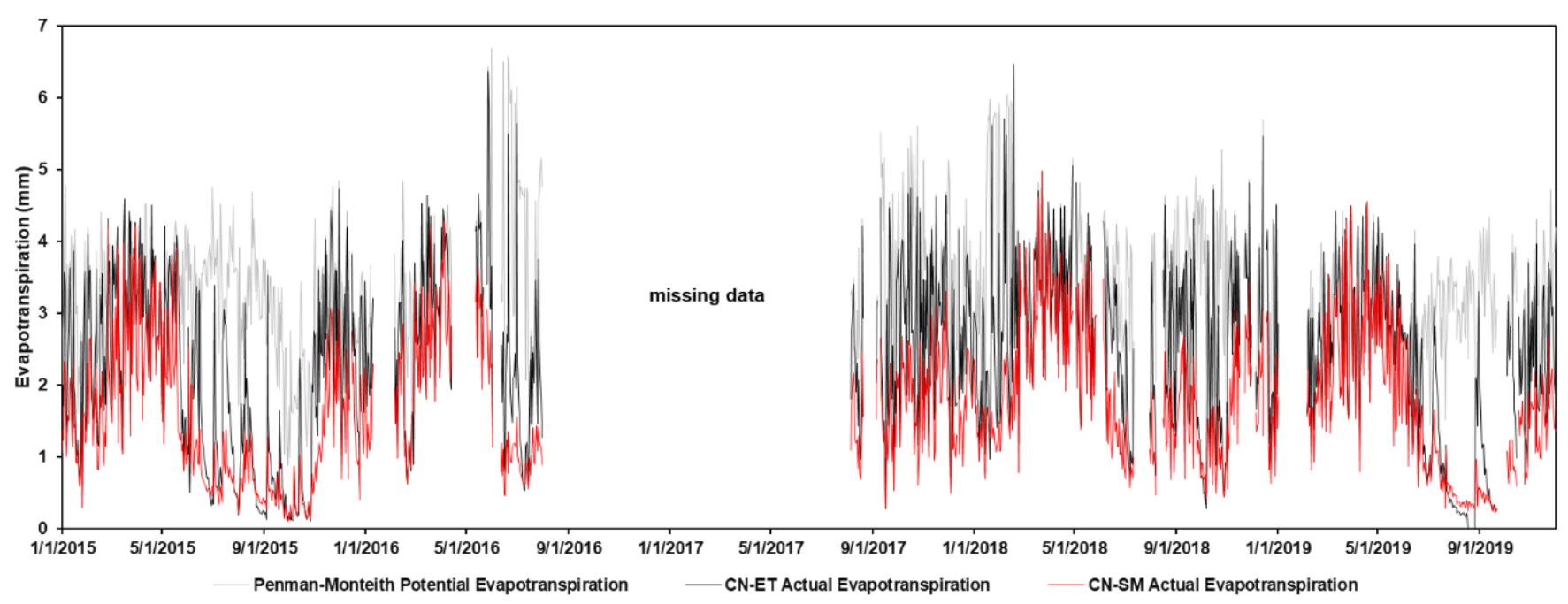

Figure 5. CN-SM and CN-ET actual evapotranspiration output during the 2015-2019 simulation period

depends on selecting a suitable PET method for the study area. Compared to CN-SM, the CN-ET simulation error is generally more significant, especially during the validation period. However, there are several peak streamflow events that the two approaches are unable to simulate accurately. CN-SM produces a slightly higher peak streamflow than $\mathrm{CN}-\mathrm{ET}$ and is relatively close to the observational data.

The objective function used in the calibration and validation is NSE, which means that the parameter values will be optimized from their initial values through several iterations until they reach the desired NSE value. When the system calculates the NSE value, it also adjusts other statistical values like R2 automatically. Parameter's initial values are available in the SWAT2012 database, and some of them are updated based on field measurements, such as SOL_K, SOL_BD, SOL_CBN, and SOL_AWC. The optimal parameter values and their best-fit value are presented in Table 4. During calibration, there is a new parameter value that replaces its initial value (marked with "v_"), and some change relatively from their initial values (marked with "r_"). The sign "r_" usually for parameters whose values vary for each specific condition, so the change will be relative to customize each condition. The "r_" sign is usually used to calibrate parameters whose values vary for each type, such as soil type and land cover. Even though the calibrated parameters are identical, except for CNCOEF, there is a difference in the best-fit value, indicating that different models will apply The "r_" sign is usually used to calibrate parameters whose different parameter combinations. The main difference between $\mathrm{CN}-\mathrm{SM}$ and $\mathrm{CN}-\mathrm{ET}$ is the conceptual structure in calculating the retention parameter (S) so that the best-fit value obtained for estimating retention parameters will have implications for other hydrological processes.
Due to differences in conceptual structure, optimization of CN-SM and CN-ET parameters causes different best-fit values for all parameters. Based on Table 4, one of the optimized sensitive parameters that need more attention because it directly relates to the model's structural uncertainty is SOL_Z. Apart from SOL_Z, the other parameters' best-fit value still makes sense in describing the biophysical conditions of the study area. During optimization, CN-SM SOL-Z does not change much from the initial value. At the same time, CN-ET SOL-Z changed about two-thirds of its initial value. Acrisols in the tropical lowland landscape have higher SOL_Z or classified on deep soil, even though its absolute value in the study has not been measured. The CN-ET's inability to describe SOL_Z in the study area is a weakness in implementing CN-ET due to its conceptual structure. A possible reason is that the CN-ET developed for shallow soils ostensibly simulates the runoff generation in the study area in shallow soil conditions (SOL_Z $<500 \mathrm{~mm}$ ) (Kannan et al., 2008). Otherwise, CN-SM simulates runoff generation under deep soil conditions (SOL_Z > $500 \mathrm{~mm}$ ). $\mathrm{CN}-\mathrm{ET}$ and $\mathrm{CN}-\mathrm{SM}$ have the same conceptual structure in simulating streamflow but very different when describing SOL_Z and simulating soil water storage. Although CN-ET and CN-SM simulated streamflow in the same magnitude, they simulated soil water storage in different quantities. These similarities and differences then lead to different interpretations of water regulation services if the two approaches are not adequately evaluated.

\section{Implication on Water Regulation Services Assessment}

Parameters optimization during the calibration process can produce streamflow output that is identical to observational data regardless of how the best-fit parameters affect other hydrological processes impre- 
Table 5. Comparison of the annual water regulation services components and indicators among two SCS-CN approaches.

\begin{tabular}{lcc}
\hline & CN-SM & CN-ET \\
\hline Input & & \\
Precipitation (mm) & 2156.7 & 2156.7 \\
Potential Evapotranspiration (mm) & 1050.7 & 1050.7 \\
\hline Output & & \\
Water Yield (mm) & 1683.0 & 1442.1 \\
Baseflow (mm) & 4.1 & 0 \\
Surface Runoff (mm) & 1602.6 & 1130.5 \\
Lateral Flow (mm) & 15.0 & 13.7 \\
Actual Evapotranspiration (mm) & 535.7 & 754.5 \\
Percolation (mm) & 23.7 & 263.9 \\
\hline Indicator & & \\
Surface Runoff/Water Yield & 0.95 & 0.78 \\
Surface Runoff/Precipitation & 0.74 & 0.52 \\
Water Yield/Precipitation & 0.78 & 0.67 \\
Actual/Potential Evapotranspiration & 0.51 & 0.72 \\
Actual & 0.25 & 0.35 \\
Evapotranspiration/Precipitation & & \\
\hline
\end{tabular}

cision. In several studies, when the objective func-tion defined in calibration achieves categories satis-factorily the streamflow output will be interpreted in various scenarios. For example, both approaches can be relied on to evaluate the impacts of land-use change and climate change on streamflow. However, because this research is related to the assessment of water regulatory services, the model's interpretation is based not only on streamflow outputs but also on other water regulation services such as soil water storage and actual evapotranspiration. So, the uncertainty of $\mathrm{CN}-\mathrm{SM}$ and $\mathrm{CN}-\mathrm{ET}$ in simulating soil water storage and actual evaporation should be evaluated to minimize the output's misinterpretation. SWAT simulates soil moisture for each HRU as soil water storage $(\mathrm{mm})$ in unsaturated conditions or available water content (AWC) between permanent wilting point (WP) and field capacity (FC). To get \%v/v soil moisture in available water content, SWAT divides the soil water storage $(\mathrm{mm})$ by soil depth (SOL_Z) and adds this result with water content at the permanent wilting point.

The previous discussion has explained that $\mathrm{CN}$ ET simulates low soil water storage based on its best-fit parameters, especially for SOL_Z. As a result, the soil moisture dynamic $(\Delta S)$ at available water content becomes higher to compensate for higher capillary flow. It happens because the potential matrix $(\psi \mathrm{m})$ related to the soil surface tension forces of unsaturated soil water is preponderant for shallow soils (relationship between free energy gradient and soil depth). CN-SM simulates available soil moisture in the range from $17.7 \% \mathrm{v} / \mathrm{v}$ (WP) to $25.7 \% \mathrm{v} / \mathrm{v}$ (FC). On the other hand, $\mathrm{CN}$-ET simulates available soil moisture range from $12.1 \% \mathrm{v} / \mathrm{v}(\mathrm{WP})$ to $20.1 \% \mathrm{v} / \mathrm{v}$ (FC). Compared with lab- oratory test results, where the WP and FC in the study area are $16.9 \pm 3.6 \% \mathrm{v} / \mathrm{v}$ and $26.3 \pm 1.75 \% \mathrm{v} / \mathrm{v}$, respectively, $\mathrm{CN}-\mathrm{SM}$ has a more reasonable WP and FC value than $\mathrm{CN}-\mathrm{ET}$. However, both methods have the same AWC range, which is $\approx 0.8 \% \mathrm{v} / \mathrm{v}$. The difference between their WP and FC causes different soil water flux interpretations at the same $\% v / v$ soil moisture condition. If $\% \mathrm{v} / \mathrm{v}$ is above $\mathrm{FC}$ or when the soil is saturated, excess water will be percolated into the groundwater layer due to higher gravitational force than other forces. If \%v/v is in the AWC range as shown in Figure 4, available water will move capillary to the soil surface to compensate for soil evaporation and plant transpiration. Furthermore, if \%v/v is below the WP, soil matrix suction will dominate so that water cannot move horizontally or vertically.

Based on the water balance equation, differences in soil water dynamics at the same river discharge and rainfall cause differences in the actual evapotranspiration value $\left(E_{a}=P-Q-\Delta S\right)$. The magnitude of actual evapotranspiration is a function of the energy required to evaporate water (PET), crop parameters related to the transpiration process, and water availability for the evaporation process (available soil moisture). So, the maximum value of actual evapotranspiration is the same as the PET when the soil water content in field capacity. Otherwise, the minimum value of actual evapotranspiration is zero when the soil water content in a permanent wilting point. At the same potential evapotranspiration conditions, the higher actual evapotranspiration is associated with higher soil water changes to compensate for capillary flow. Therefore, CN-ET's imprecision in simulating higher soil water changes then implicates the overestimated actual evapotranspiration (Figure 5). Based on that value, we can see that CN-ET is much worse at simulating other water regulation services components than CN-SM, although it is equally good at simulating streamflow. Apart from model comparisons, one of the transpiration-related crop parameters that affect the oil palm's actual evapotranspiration is the leaf area index (LAI). We know that mature oil palms with a high LAI value also have a higher actual evapotranspiration rate than young oil palms. Because actual evapotranspiration is simulated for each HRU (not individual plant), we used the mature oil palms environment LAI value of $1.2 \mathrm{~m} 2 / \mathrm{m} 2$ that derived from the mean of below canopies LAI and harvest path LAI value to control the amount of actual evapotranspiration and soil moisture dynamics for these each HRUs.

Water regulation services assessment in an ecosystem generally compares one of the water flow components to others, such as the ratio of surface runoff to water yield, surface runoff to rainfall, water 
yield to rainfall, actual evapotranspiration to rainfall, and actual to potential evapotranspiration. This comparison illustrates indicators related to the water regulation services sustainability, such as water regulation services are sustainable in a high ratio or even sustained at a low ratio. Table 5 shows the difference annual mean value of CN-SM and CN-ET water regulation component and their sustainability indicators. Due to the difference between CN-SM and $\mathrm{CN}-\mathrm{ET}$ in simulating water regulation services components, the relative relationship between these components is automatically different, so that the interpretation of these sustainability indicators will also be different. Therefore, choosing an approach that can simulate water regulation services precisely and appropriately to the study area's biophysical characteristics is crucial to note before simulation. CN-ET, which is not suitable for application in the study area, may be more appropriate for water regulation services assessment in other areas with shallow soils. Otherwise, CN-SM effectively assesses water regulation services in deep soil but may not be as reliable in shallow soil (Kannan et al. 2008). The structure of the CN-ET model, which is developed to simulate rapid soil moisture dynamics as it occurs in shallow soils, causes an overestimated simulation of groundwater dynamics in the study area. Because the water balance is based on the law of mass conservation, if one component cannot be appropriately described, it will affect the misfit in the value of the other components. It is important to be considered because the accuracy of the simulation results significantly affects watershed management recommendations to improve water management services' sustainability.

\section{CONCLUSIONS}

The curve number $(\mathrm{CN})$ method is a simple rainfall-runoff transformation method that only requires daily rainfall data $(P)$ and watershed curve number that derived from land use, soil, and slope data but powerful to estimate excess rainfall as surface runoff. There are two different approaches for calculating the daily $\mathrm{CN}$ with the same input data, soil moisture curve number (CN-SM) as an original approach and plant evaporation curve number (CN-ET) as a modified approach. This study compared CN-SM and CN-ET in the SWAT model to evaluate their reliability and uncertainty in simulated water regulation services in an intermittent micro-catchment dominated by monoculture plantations with Acrisols soil. Through the calibration and validation process with 150 daily observation streamflow data, both approaches can estimate streamflow very well, as evidenced by high NSE and R2 values and acceptable uncertainty, as evidenced by P-Factor $>70 \%$ and R-Factor $<1$. A comparison of daily $\mathrm{CN}-\mathrm{ET}$ and $\mathrm{CN}-\mathrm{SM}$ streamflow during the simulation period also shown that both outputs are almost identical with high R2, so that both approaches can be chosen as an alternative in modeling streamflow. However, the CN-SM and CN-ET's conceptual structure differences cause differences in the calibrated parameters' best-fit value and their sensitivity to streamflow simulations. CN2, ALPHA_BNK, CH2, ESCO, SOL_Z, $\mathrm{CH}_{-} \mathrm{N} 2$, and RCHRG_DP are equally sensitive for $\mathrm{CN}-\mathrm{ET}$ and CN-SM. SOL_BD and GWQMN are only sensitive to CN-SM. On the other hand, SOL_AWC and CNCOEF are only sensitive to $\mathrm{CN}-\mathrm{ET}$. There is no problem with $\mathrm{CN}$ SM's best-fit value during parameter optimization, but $\mathrm{CN}$-ET cannot describe SOL_Z in the study area well. CN-ET developed for shallow soil simulates the runoff generation in the study area in shallow soil conditions (SOL_Z < $500 \mathrm{~mm}$ ), while CN-SM describes SOL_Z adequately where the characteristic of Acrisol soil is deep soil (SOL_Z > $500 \mathrm{~mm}$ ). Therefore, although $\mathrm{CN}$ ET and CN-SM simulated streamflow in the same magnitude, they simulated soil water storage dynamics in different quantities. CN-ET's inability to describe the study area's biophysical conditions well implicates low soil water storage and high soil water dynamics simulation, and that condition results in overestimated actual evapotranspiration. These output similarities and differences then lead to different interpretations of water regulation sustain-ability if we do not adequately evaluate those approaches. As a result, selecting a runoff curve number approach, which can replicate precision water regulation services and suit for describing the characteristics of the study area, is essential to be considered. The accuracy of the simulation results significantly affects watershed management recommendations to improve water regulations' sustainability.

\section{ACKNOWLEDGEMENT}

This research was supported by PMDSU (Program Pendidikan Magister Menuju Doktor Untuk Sarjana Unggul) scholarship in terms of funding and the CRC-990 EFForTS (Collaborative Research Center 990 Ecological and Socioeconomic Functions of Tropical Lowland Rainforest Transformation System) in terms of access permits in the study area and provision of daily meteorological data.

\section{REFERENCES}

Abbaspour, K.C., 2015. SWAT Calibration and Uncertainty Programs. Swiss Federal Institute of Aquatic Science and Technology, Dübendorf. Abbaspour, K.C., Vaghefi, S.A., Srinivasan, R., 2018. A Guideline for Successful Calibration and 
Uncertainty Analysis for Soil and Water Assessment: A Review of Papers from the 2016 International SWAT Conference. Water 10, 6. https://doi.org/10.3390/w10010006

Ajmal, M., Waseem, M., Kim, D., Kim, T.-W., 2020. A Pragmatic Slope-Adjusted Curve Number Model to Reduce Uncertainty in Predicting Flood Runoff from Steep Watersheds. Water 12 1469. https://doi.org/10.3390/w12051469

Anees, M.T., Abdullah, K., Nawawi, M.N.M., Ab Rahman, N.N.N., Piah, Abd.R.Mt., Zakaria, N.A., Syakir, M.I., Mohd. Omar, A.K., 2016. Numerical modeling techniques for flood analysis. Journal of African Earth Sciences 124, 478-486. https://doi.org/10.1016/j.jafrearsci.2016.10.00 1

Arnold, J.G., Srinivasan, R., Muttiah, R.S., Williams, J.R., 1998. Large Area Hydrologic Modeling and Assessment Part I: Model Development1. JAWRA Journal of the American Water Resources Association 34, 73-89. https://doi.org/10.1111/j.17521688.1998.tb05961.x

Ayele, G.T., Teshale, E.Z., Yu, B., Rutherfurd, I.D., Jeong, J., 2017. Streamflow and Sediment Yield Prediction for Watershed Prioritization in the Upper Blue Nile River Basin, Ethiopia. Water 9, 782. https://doi.org/10.3390/w9100782

Ba, W., Du, P., Liu, T., Bao, A., Chen, X., Liu, J., Qin, C., 2020. Impacts of climate change and agricultural activities on water quality in the Lower Kaidu River Basin, China. J. Geogr. Sci. 30, 164-176. https://doi.org/10.1007/s11442-020$1721-z$

Baiamonte, G., 2019. SCS Curve Number and GreenAmpt Infiltration Models. Journal of Hydrologic Engineering 24, 04019034. https://doi.org/10.1061/(ASCE)HE.19435584.0001838

Brito, D., Neves, R., Branco, M.A., Prazeres, Â., Rodrigues, S., Gonçalves, M.C., Ramos, T.B., 2019. Assessing Water and Nutrient Long-Term Dynamics and Loads in the Enxoé Temporary River Basin (Southeast Portugal). Water 11, 354. https://doi.org/10.3390/w11020354

Chen, Y., Niu, J., Sun, Y., Liu, Q., Li, S., Li, P., Sun, L., Li, Q., 2020. Study on streamflow response to land use change over the upper reaches of Zhanghe Reservoir in the Yangtze River basin. Geoscience Letters 7, 6. https://doi.org/10.1186/s40562-020-00155-7

Cheng, Q.-B., Reinhardt-Imjela, C., Chen, X., Schulte, A., $\mathrm{Ji}, \quad \mathrm{X}$. , Li, F.-L., 2016. Improvement and comparison of the rainfall-runoff methods in
SWAT at the monsoonal watershed of Baocun Eastern China. Hydrological Sciences Journal. https://doi.org/10.1080/02626667.2015.10514 85

Dash, S.S., Sena, D.R., Mandal, U., Kumar, A., Kumar, G., Mishra, P.K., Rawat, M., 2020. A hydrological modelling-based approach for vulnerable area identification under changing climate scenarios. Journal of Water and Climate Change 12, 433-452. https://doi.org/10.2166/wcc.2020.202

Gao, X., Chen, X., Biggs, T.W., Yao, H., 2018. Separating Wet and Dry Years to Improve Calibration of SWAT in Barrett Watershed, Southern California. Water 10, 274 https://doi.org/10.3390/w10030274

Hawkins, R.H., Theurer, F.D., Rezaeianzadeh, M., 2019. Understanding the Basis of the Curve Number Method for Watershed Models and TMDLs. Journal of Hydrologic Engineering 24, 06019003. https://doi.org/10.1061/(ASCE)HE.19435584.0001755

Hazrina, M., Risdiyanto, I., 2018. Spatial Distribution of Dryness on Oil Palm Plantations Using Landsat image. Agromet 32, 51-61. https://doi.org/10.29244/j.agromet.32.2.51-61

June, T., Dewi, N.W.S.P., Meijide, A., 2018. Comparison of Aerodynamic, Bowen-Ratio, and PenmanMonteith Methods in Estimating Evapotranspiration of Oil Palm Plantation. Agromet 32, 11-20. https://doi.org/10.29244/j.agromet.32.1.11-20

Kannan, N., Santhi, C., Williams, J.R., Arnold, J.G., 2008. Development of a continuous soil moisture accounting procedure for curve number methodology and its behaviour with different evapotranspiration methods. Hydrological Processes 22, 2114-2121. https://doi.org/10.1002/hyp.6811

Karlberg, L., Dile, Y., 2016. Investigation of the curve number method for surface runoff estimation in tropical regions. https://doi.org/10.1111/1752-1688.12446

Kii, M.I., June, T., Santikayasa, I.P., 2020. Dynamics Modeling of CO2 in Oil Palm. Agromet 34, 42 54 .

Li, X., Cheng, G., Lin, H., Cai, X., Fang, M., Ge, Y., Hu, X., Chen, M., Li, W., 2018. Watershed System Model: The Essentials to Model Complex Human-Nature System at the River Basin Scale. Journal of Geophysical Research: Atmospheres 123, 3019-3034. https://doi.org/10.1002/2017JD028154 
Liu, J., Engel, B.A., Wang, Y., Wu, Y., Zhang, Z., Zhang, M., 2019. Runoff Response to Soil Moisture and Micro-topographic Structure on the Plot Scale. Sci Rep 9, 2532. https://doi.org/10.1038/s41598-019-39409-6

Merten, J., Röll, A., Guillaume, T., Meijide, A., Tarigan, S., Agusta, H., Dislich, C., Dittrich, C., Faust, $H_{\text {., }}$ Gunawan, D., Hein, J., Hendrayanto, Knohl, A., Kuzyakov, Y., Wiegand, K., Hölscher, D., 2016. Water scarcity and oil palm expansion: social views and environmental processes. Ecology and Society 21. https://doi.org/10.5751/ES08214-210205

Moriasi, D., Arnold, J., Van Liew, M., Bingner, R., Harmel, R.D., Veith, T., 2007. Model Evaluation Guidelines for Systematic Quantification of Accuracy in Watershed Simulations. Transactions of the ASABE 50. https://doi.org/10.13031/2013.23153

Neitsch, S.L., Arnold, J.G., Kiniry, J.R., Williams, J.R., 2015. Soil and water assessment tool theoretical documentation version 2005. Texas Water Resources Institute.

Soulis, K.X., 2021. Soil Conservation Service Curve Number (SCS-CN) Method: Current Applications, Remaining Challenges, and Future Perspectives. Water 13, 192. https://doi.org/10.3390/w13020192

Sun, Z., Lotz, T., Chang, N.-B., 2017. Assessing the longterm effects of land use changes on runoff patterns and food production in a large lake watershed with policy implications. J Environ Manage 204, 92-101. https://doi.org/10.1016/j.jenvman.2017.08.043

Tarigan, S., Stiegler, C., Wiegand, K., Knohl, A., Murtilaksono, K., 2020. Relative contribution of evapotranspiration and soil compaction to the fluctuation of catchment discharge: case study from a plantation landscape. Hydrological Sciences Journal 65, 1239-1248. https://doi.org/10.1080/02626667.2020.17392 87

Tarigan, S., Wiegand, K., Sunarti, Slamet, B., 2018. Minimum forest cover required for sustainable water flow regulation of a watershed: a case study in Jambi Province, Indonesia. Hydrology and Earth System Sciences 22, 581-594. https://doi.org/10.5194/hess-22-581-2018

Verma, S., Verma, R.K., Mishra, S.K., Singh, A., Jayaraj, G.K., 2017. A revisit of NRCS-CN inspired models coupled with RS and GIS for runoff estimation. Hydrological Sciences Journal 62, 1891-1930.

https://doi.org/10.1080/02626667.2017.13341 66

Wang, B., Luo, X., Yang, Y.-M., Sun, W., Cane, M.A., Cai, W., Yeh, S.-W., Liu, J., 2019. Historical change of El Niño properties sheds light on future changes of extreme El Niño. Proceedings of the National Academy of Sciences 116, 2251222517.

Wei, Z., Zhang, B., Liu, Y., Xu, D., 2018. The Application of a Modified Version of the SWAT Model at the Daily Temporal Scale and the Hydrological Response unit Spatial Scale: A Case Study Covering an Irrigation District in the Hei River Basin. Water 10, 1064. https://doi.org/10.3390/w10081064

Widodo, I.T., Dasanto, B.D., 2010. Estimasi Nilai Lingkungan Perkebunan Kelapa Sawit Ditinjau dari Neraca Air Tanaman Kelapa Sawit (Studi Kasus: Perkebunan Kelapa Sawit di Kecamatan Dayun, Kabupaten Siak, Propinsi Riau) Agromet 24, 23-32.

Widyastuti, M.T., Taufik, M., 2019. Long-term Monthly Discharge Prediction for Cimanuk Watershed. Agromet 33, 96-104. https://doi.org/10.29244/j.agromet.33.2.96104

Zanin, P.R., Bonuma, N.B., Corseuil, C.W., 2018. Hydrosedimentological modeling with SWAT using multi-site calibration in nested basins $\begin{array}{lll}\text { with } & \text { reservoirs. }\end{array}$ https://doi.org/10.1590/23180331.231820170153

Zhang, D., Lin, Q., Chen, X., Chai, T., 2019. Improved Curve Number Estimation in SWAT by Reflecting the Effect of Rainfall Intensity on Runoff Generation. Water 11, 163. https://doi.org/10.3390/w11010163 